\title{
DIVISÃO DE EDUCAÇÃO
}

\section{COMITÉ DA IUPAC \\ PARA O ENSINO DA QUÍMICA}

\section{- DUAS NOTAS}

Veículo de comunicação:

\section{INTERNATIONAL NEWSLETTER ON CHEMICAL EDUCATION}

O veículo de comunicação do comité da IUPAC para o ensino da química é a International Newsletter on Chemical Education. Na sede da SPQ em Lisboa existem os números 3, 6 e 9 a 13, e exemplares dos números 9,11 , 12 e 13 foram enviados para os Departamentos de Química (ou para as Bibliotecas) das Faculdades de Ciências de Lisboa, Porto e Coimbra das Universidades do Minho e de Aveiro e dos Institutos de Vila Real e Évora e para algumas escolas secundárias. Da Newsletter podem extrair-se artigos na versão original ou em tradução e, desde que seja feita referência ao original não há necessidade de pedir autorização aos editores

Sugestão ao leitor: logo que possa procure e folheie a «Newsletter» e comunique-nos o possível interesse de no boletim da SPQ, disseminarmos informações contidas na «Newsletter».

\section{Projectos}

O comité da IUPAC para o ensino da Química tem actualmente em consideração vários projectos. No caso de mostrar interesse em tomar parte nalgum deles escreva directamente aos proponentes dos projectos, que são os seguintes:

1) Computadores em Educação em Química

Prof. L. Paoloni

Un. di Palermo

Via Archirafi 20

90123 Palermo - Sicília
2) Produção local do equipamento:

Prof. D.J. Waddington

Department of Chemistry - University of York

Heslington - York Y01 - 50D

U.K.

3) Projecto para uma abordagem integrada do ensino da química a nível universitário.

Prof. G. Illuminati

Instituto di Química - Un. di Roma

I - 00185 Roma

Itália

4) Experiências simples

Prof. A. Guerrero

Santa Fe 2879, 1B

1425 Buenos Aires

Argentina

5) Projecto de educação em química como parte da cultura

Prof. L. Paoloni

Un. di Palermo

Via Archirafi - 20

90123 Palermo

Sicília

Nota: na sede da SPQ, em Lisboa, pode consultar resumos destes projectos. Contacte com Mariana Pereira - Av. Combatentes da Grande Guerra 15-1. ${ }^{\circ}$ D 2700 Amadora - telef. 942542 - que lhe fornecerá indicações sobre os mesmos. 


\section{EDUCAÇÃO EM QUÍMICA - novos livros -}

1. Chemical education in the coming decades problems and challenges (antologia com 298p. editada em 1977 pela Prof. A. Kornhauser)

Trata-se de uma antologia relativa a dois encontros realizados em Agosto de 1977 em Ljubljana, Jugoslávia: estes encontros foram organizados numa tentativa de chamar a atenção para problemas e iniciativas em educação em química nas décadas futuras. A antologia contém as palestras apresentadas, bem como resumos das discussoes que se lhe seguiram, onde se apontam sugestões para o futuro que são arrojadas mesmo para os países que tem um plano de ensino bem desenvolvido.

Esta antologia, ao preço de $\$ 15$, pode obter-se através de DDU Univerzum, Parmova 39, PO Box 106

61001 Ljubljana, Jugoslávia

2. The teaching of Chemistry - interaction between secondary and tertiary levels

(antologia com 175p. editada em 1980 por P.E. Childs e J.E. Gowan)

Esta antologia da $5 .^{a}$ Conferência Internacional sobre Educação em Química, patrocinada pela IUPAC, realizada em Agosto de 1979 em Dublin, para além das conferências plenárias e resumos das discussões sobre os mesmos temas das conferências que foram debatidas em 12 grupos de trabalho, inclui resumos dos 75 cartazes exibidos que os editores agruparam em 6 temas, a saber:

- investigação em educação em química (15);

- ensino da química (14);

- meios usados no ensino da química (10);

- novos cursos de química (14);

- formação de professores de química (5);

- aspectos gerais e sociais de educação em química

Pode obter-se a antologia através de:

Mr. P.A. Start

University College, Dublin, Ireland
3. Chemical Education in the 70's

(antologia patrocinada pelo comité da IUPAC para o ensino da Química e editada por C.N. Rao, D.J. Waddington e A. Kornhauser)

Esta publicação inclui contribuições de 40 países sobre desenvolvimentos em educação em química em escolas e universidades durante cinco anos (1973 - 1977) com especial realce para inovações e novos programas de Química. Foram pedidas contribuições para as quatro secções a seguir indicadas:

i. ensino ao nível da escola primária e secundária;

ii. ensino ao nível do terciário;

iii. treino nas indústrias químicas e afins

iv. química e sociedade

Há ainda artigos resumindo as contribuições recebidas e apresentando uma previsão para o futuro. $\mathrm{O}$ texto contém informações sobre alterações recentes no curriculo, técnicas de avaliação de conhecimentos e outros aspectos importantes no ensino da química.

$O$ livro pode ser adquirido ao preço de $6(£ 5 .+£ 1$ para embalagem e correio) através de:

Prof. D. J. Waddington

Department of Chemistry - University of York

Heslington - York Y01 5DD - U.K.

\section{Teaching school chemistry (em preparação)}

Este livro destina-se a professores do secundário, a professores de formação de professores e a planeadores de currícula e inclui secções sobre

i. mudança de face da Química;

ii. desenvolvimento curricular;

iii. métodos de ensino e apredizagem;

iv. técnicas em ensino e aprendizagem;

v. avaliação de alunos;

vi. formação de professores;

vii. investigação

viii. o futuro

O livro encontra-se em fase de preparação.

\title{
PALESTRAS DE QUÍMICA $\left(12 .^{\circ}\right.$ ANO)
}

\author{
Zona Norte
}

\section{Local: Anfiteatro de Química da Faculdade de Ciências} do Porto

Duração: 14 h30 - 15H45, 45 minutos para discussão

\footnotetext{
1 - Átomo de Hidrogénio - 11 de Março - Prof. 4 - Espectroscopia - 29 de Abril - Prof. Doutor Doutor A. Amaral Ferreira Gomes

2 - Ligação Química - 25 de Março - Prof. Doutor 5 - Termodinâmica Química - 6 de Maio - Prof. A. Amaral Doutor Ribeiro da Silva

3 - Espectroscopia - 22 de Abril - Prof. Doutor 6 - Termodinâmica Química - 20 de Maio - Prof. Ferreira Gomes Doutor Ribeiro da Silva
} 